\title{
Rating access to health care: Are there differences according to geographical region?
}

\author{
Abstract \\ Objective: To report on satisfaction with \\ access to health care in Queensland \\ focussing on regional differences. \\ Methods: A sub-sample of 4440 \\ respondents with no history of cancer \\ from the Queensland Cancer Risk Study \\ who completed a self-administered \\ questionnaire was used for this study. \\ Main outcome measures: Perceptions of \\ overall difficulty gaining access to health \\ care and ratings of access to various \\ health care services by region. \\ Results: Queenslanders living outside \\ major cities reported less satisfaction with \\ access to various aspects of health care \\ services. Age was associated with more \\ favourable ratings of health care access.
} Conclusions: Despite public health efforts to increase service provision throughout Queensland, health care access is still rated relatively less favourably by Queenslanders in regional and remote parts of the state.

Implications: Identifying which services are difficult to access and why will assist public health policy makers in improving health service accessibility.

Keywords: health services accessibility, healthcare disparities, rural health services, geography.

Aust N Z Public Health. 2008; 32:246-9 doi: 10.1111/j.1753-6405.2008.00223.x

\author{
Katrin Hausdorf, Carla Rogers \\ Viertel Centre for Research in Cancer Control, The Cancer Council Queensland

\section{David Whiteman} \\ Comprehensive Cancer Research Centre, Queensland Institute of Medical \\ Research
}

\section{Beth Newman}

School of Public Health, Institute of Health and Biomedical Innovation, Queensland University of Technology

\section{Peter Coxeter, Philippa Youl, Joanne Aitken \\ Viertel Centre for Research in Cancer Control, The Cancer Council Queensland}

i

n Australia, living outside a major city is associated with a number of disadvantages in terms of health outcomes and access to health care. An extensive body of research has demonstrated that Australians living outside major cities tend to have increased levels of health risk factors as well as reduced access to health care services. ${ }^{1}$ Addressing these inequalities is central to Australia's health policy and the focus of considerable public health efforts.

Access to health services for regional Australia has been examined nationally in terms of accessibility and supply of health workers $^{1}$ and on a state-specific level in terms of health services utilisation ${ }^{2-4}$ and accessibility. ${ }^{3}$ While these factors give a good indication of service availability, they do not provide insight into the community's perception of, and satisfaction with, these services. Satisfaction with access to health care has been identified as a critical factor in identifying rural and remote health care needs. ${ }^{5}$ Individual ratings of access to health care services have not been widely examined. One study that examined satisfaction with health care in two rural communities concluded that satisfaction with access to general practitioner (GP) services was the most important indicator of a community's happiness with the accessibility of health care. ${ }^{6}$

Queensland has one of the fastest growth rates of all states and territories in Australia. Additionally, it is the most decentralised state with over half the population living outside the Brisbane metropolitan area. ${ }^{7}$ The aim of this study was to examine ratings of access to various health services for a large sample of Queenslanders, with a particular focus on differences across geographic regions.

\section{Methods}

\section{Sample and Procedures}

The Queensland Cancer Risk Study (QCRS) was a state-wide, population-based survey of 9419 English-speaking residents of Queensland aged 20-75 years. Participants were sampled at random within strata defined by sex, age group and geographic region. Methods are described in detail elsewhere. ${ }^{8}$ The demographic characteristics of the weighted survey sample were similar to the Queensland population ${ }^{2}$ for gender, age, residential region and country of origin.

Submitted: October 2007 Revision requested: November 2007 Accepted: April 2008 
Respondents had a higher level of education, were more likely to be married and had more personal experience with cancer than the Queensland population. There was an under-representation of Indigenous people in the survey sample.

A sub-sample of 5,608 respondents (59.5\%) completed a self-administered questionnaire which examined attitudes and perceptions towards cancer risk and health behaviours. Items relating to difficulty gaining access, and ratings of access to health care, were the focus of this analysis. Respondents with a history of cancer were excluded thus leaving an overall sample of 4,439.

\section{Measures}

Demographic characteristics previously identified as key correlates for access to and utilisation of health services ${ }^{5,9}$ included private health insurance; employment status; and gross household income.

Respondents were classified according to the Accessibility and Remoteness Index for Australia (ARIA+), which is based on physical road distance to the nearest town of 1000 or more people. ${ }^{10}$ ARIA+ classifications include: major city, inner regional, outer regional, remote and very remote. These latter two categories were combined due to small numbers of participants in very remote areas.

Overall difficulty gaining access to health care was examined by the item "Are there any health services to which you have had trouble gaining access?" (responses 'yes' or 'no'). Using a likert scale from 1 (excellent) to 5 (poor) respondents were asked to rate their access to medical specialists, hospital, a GP who bulk bills, after-hours medical care and the hours a GP is available.

\section{Data Analysis}

Using SPSS, ${ }^{11}$ logistic regression was used to calculate odds ratios (OR) and 95\% confidence intervals $(95 \% \mathrm{CI})$ to estimate the association between identified correlates (sex, age, private health insurance, employment, gross household income and ARIA+) and overall difficulty accessing health care (yes/no).

To examine ratings of specific aspects of health care, separate multinomial logistic regression analyses were performed for each of the health care items using the correlates described above. Health service ratings were collapsed from a five-point scale into 'excellent/very good', 'good/fair' and 'poor', with 'excellent/very good' defined as the reference category.

\section{Results}

The sample consisted of 4,440 adults with $50.1 \%$ female and an average age of 49 years. The majority of respondents lived in a major city (43.6\%), while $29.2 \%$ lived in inner regional, $24.8 \%$ in outer regional and $2.4 \%$ in remote/very remote areas. More than (55.3\%) had private health insurance, and $60.1 \%$ were employed either for self or wages. The majority $(60.7 \%)$ reported a household income of between $\$ 20,001$ and $\$ 80,000$.
In a fully adjusted model, geographic region was significantly associated with perceived difficulty in accessing health care (Table 1). Respondents who lived in remote/very remote areas were significantly more likely to report difficulty accessing health services than those living in a major city (odds ratio (OR) 4.3, 95\% Confidence Interval (CI) 2.72-6.80). Those in inner or outer regional areas also reported significantly increased likelihood of difficulty gaining access to health services (OR 1.27, 95\% CI 1.01-1.60 and OR 1.80, 95\% CI 1.43-2.26 respectively). Other factors associated with difficulty in accessing health services included being unemployed and a lack of private health insurance (OR 1.36, 95\% CI 1.08-1.73 and OR 1.49, 95\% CI 1.22-1.82). Respondents aged 60 to 75 years were significantly less likely to a report difficulties accessing health care (OR $0.61,95 \% \mathrm{CI}$ 0.46-0.80).

Compared to those aged 20 to 39 years, older respondents were significantly less likely to rate as poor access to a medical specialist (OR 0.51, 95\% CI 0.36-0.72), access to a GP who bulk billed (OR $0.52,95 \%$ CI $0.41-0.65$ ) and access to a hospital (OR 0.73, 95\% CI 0.61-0.88) (Table 2).

Lower income and lack of private health insurance were associated with poorer ratings of access to a medical specialist (OR 2.24, 95\% CI 1.46-3.44 and OR 2.70, 95\% CI 2.11-3.44) and a hospital (OR 3.85, 95\% CI 2.08-7.11 and OR 2.67, 95\% CI 1.91-3.73).

Table 1: Adjusted odds ratios for difficulty gaining access to health care in Queensland respondents. ${ }^{\mathrm{a}}$

\begin{tabular}{|c|c|c|c|}
\hline & $\mathbf{N}$ & OR & $95 \% \mathrm{Cl}$ \\
\hline \multicolumn{4}{|l|}{ Sex } \\
\hline Female & 2226 & 1.00 & \\
\hline Male & 2213 & 0.94 & $0.78-1.14$ \\
\hline \multicolumn{4}{|l|}{ Age group (years) } \\
\hline $20-39$ & 1340 & 1.00 & \\
\hline $40-59$ & 1603 & 0.90 & $0.72-1.12$ \\
\hline $60-75$ & 1496 & $0.61^{\mathrm{e}}$ & $0.46-0.80$ \\
\hline \multicolumn{4}{|c|}{ Private health insurance } \\
\hline Yes & 2466 & 1.00 & \\
\hline No & 1973 & $1.49^{e}$ & $1.22-1.82$ \\
\hline \multicolumn{4}{|l|}{ Employed } \\
\hline Yes & 2692 & 1.00 & \\
\hline No & 1747 & $1.36^{d}$ & $1.08-1.73$ \\
\hline \multicolumn{4}{|c|}{ Gross household income } \\
\hline$>\$ 80,001$ & 900 & 1.00 & \\
\hline$\$ 20,001-\$ 80.000$ & 2693 & 0.95 & $0.73-1.22$ \\
\hline$<\$ 20,000$ & 846 & 1.21 & $0.85-1.71$ \\
\hline \multicolumn{4}{|l|}{$\mathrm{ARIA}++^{\mathrm{b}}$} \\
\hline Major city & 1943 & 1.00 & \\
\hline Inner regional & 1307 & $1.27^{c}$ & $1.01-1.60$ \\
\hline Outer regional & 1085 & $1.80^{\mathrm{e}}$ & $1.43-2.26$ \\
\hline Remote/very remote & 104 & $4.30^{e}$ & $2.72-6.80$ \\
\hline \multicolumn{4}{|c|}{$\begin{array}{l}\text { Note: } \\
\text { (a) Measured by the item "Are there any health services to which you have had } \\
\text { trouble gaining access?" Reference category = no. } \\
\text { (b) Accessibility/Remoteness Index of Australia } \\
\text { (c) }=p<0.05 \\
\text { (d) } p<0.01 \\
\text { (e) } p<0.001\end{array}$} \\
\hline
\end{tabular}


Respondents living in regional and remote areas had significantly increased odds of rating their access to medical specialists and hospitals as poor. Access to a GP who bulk billed showed similar ratings for respondents across regions. However, compared to respondents living in major cities, those living in remote or very remote areas were significantly more likely to rate the hours a GP is available as poor (OR 3.22, 95\% CI 1.73-6.00) (Data not shown).

\section{Discussion}

While access to health care services is known to be poorer for Australians living outside a major city, ${ }^{1}$ individual ratings of access to services have not previously been reported. As in earlier research, ${ }^{1}$ individual ratings of access to health care services across geographic regions in Queensland show a pattern that is largely reflective of the regional disparities in accessibility of health services and costs associated with travelling to health services. ${ }^{1}$ Compared to those living in a major city, respondents in this study who live outside a major city were up to four times more likely to report difficulty in accessing health services in general, and residents of remote and very remote areas were significantly more likely to rate their access to a hospital or medical specialists as poor.
While there is evidence that GPs are significantly more difficult to access in regional and remote areas, ${ }^{3}$ these data show that individual ratings of access to a GP who bulk billed were no different across regions. This finding may reflect a decrease in GPs who bulk-bill in all geographical areas. ${ }^{12}$ Therefore, while access to a GP may be more difficult in regional and remote areas, access to GPs who bulk bill is no more or less difficult in regional and remote areas compared with major cities. However, regional and remote respondents were significantly more likely to rate the hours a GP is available as poor.

\section{Limitations}

While the initial sample in the Queensland Cancer Risk Study was broadly representative of the Queensland population, ${ }^{8}$ results used in the current analysis were based on a self-administered questionnaire completed by a subset of the original sample. There was some bias towards over-representation of bettereducated respondents and an under-representation of indigenous individuals. ${ }^{8}$ Further, assessment of access to healthcare was measured using only a single self-report item.

Table 2: Separate fully-adjusted models examining the odds of rating access to a GP who bulk bills, access to a medical specialist and access to a hospital as good/fair or poor compared to very good/excellent.

\begin{tabular}{|c|c|c|c|c|c|c|}
\hline & \multicolumn{2}{|c|}{ Access to GP who bulk bills } & \multicolumn{2}{|c|}{ Access to medical specialist } & \multicolumn{2}{|c|}{ Access to a hospital } \\
\hline & $\begin{array}{l}\text { Good/Fair } \\
\text { OR }(95 \% \mathrm{Cl})\end{array}$ & $\begin{array}{c}\text { Poor OR } \\
(95 \% \mathrm{Cl})\end{array}$ & $\begin{array}{l}\text { Good/Fair } \\
\text { OR (95\% } \% \text { Cl) }\end{array}$ & $\begin{array}{c}\text { Poor OR } \\
(95 \% \mathrm{Cl})\end{array}$ & $\begin{array}{l}\text { Good/Fair } \\
\text { OR (95\% } \% \text { Cl) }\end{array}$ & $\begin{array}{c}\text { Poor OR } \\
(95 \% \mathrm{Cl})\end{array}$ \\
\hline \multicolumn{7}{|l|}{$\overline{\text { Sex }}$} \\
\hline Female & 1.00 & 1.00 & 1.00 & 1.00 & 1.00 & 1.00 \\
\hline Male & $1.11(0.95-1.29)$ & $0.75(0.64-0.88)$ & $1.01(0.88-1.15)$ & $0.92(0.73-1.16)$ & $1.03(0.91-1.17)$ & $1.03(0.75-1.41)$ \\
\hline \multicolumn{7}{|l|}{ Age group } \\
\hline $20-39$ years & 1.00 & 1.00 & 1.00 & 1.00 & 1.00 & 1.00 \\
\hline $40-59$ years & $0.96(0.79-1.16)$ & $1.04(0.86-1.25)$ & $0.87(0.74-1.02)$ & $1.17(0.89-1.54)$ & $1.01(0.87-1.18)$ & $1.07(0.73-1.57)$ \\
\hline $60-75$ years & $0.48(0.38-0.60)$ & $0.52(0.41-0.65)$ & $0.55(0.46-0.67)$ & $0.51(0.36-0.72)$ & $0.73(0.61-0.88)$ & $0.66(0.42-1.04)$ \\
\hline \multicolumn{7}{|c|}{ Private health insurance } \\
\hline Yes & 1.00 & 1.00 & 1.00 & 1.00 & 1.00 & 1.00 \\
\hline No & $0.92(0.78-1.08)$ & $0.64(0.55-0.76)$ & $1.75(1.52-2.00)$ & $2.70(2.11-3.44)$ & $1.79(1.57-2.05)$ & $2.67(1.91-3.73)$ \\
\hline \multicolumn{7}{|l|}{ Employed $^{a}$} \\
\hline Yes & 1.00 & 1.00 & 1.00 & 1.00 & 1.00 & 1.00 \\
\hline No & $0.78(0.64-0.95)$ & $0.65(0.54-0.80)$ & $0.92(0.78-1.09)$ & $1.05(0.78-1.41)$ & $0.90(0.77-1.06)$ & $0.91(0.61-1.36)$ \\
\hline \multicolumn{7}{|l|}{ Income $^{\text {b }}$} \\
\hline$>\$ 80,001$ & 1.00 & 1.00 & 1.00 & 1.00 & 1.00 & 1.00 \\
\hline$\$ 20,001-\$ 80,0 c$ & $01.09(0.89-1.34)$ & $1.10(0.90-1.25)$ & $1.32(1.12-1.57)$ & $1.20(0.87-1.66)$ & $1.16(0.98-1.37)$ & $1.54(0.93-2.53)$ \\
\hline$\$ 20,000$ & $0.88(0.66-1.17)$ & $0.61(0.45-0.82)$ & $1.66(1.30-2.14)$ & $2.24(1.46-3.44)$ & $1.59(1.25-2.03)$ & $3.85(2.08-7.11)$ \\
\hline \multicolumn{7}{|l|}{$A R I A+^{c}$} \\
\hline Major city & 1.00 & 1.00 & 1.00 & 1.00 & 1.00 & 1.00 \\
\hline Inner regional & $1.16(0.96-1.38)$ & $0.98(0.81-1.17)$ & $1.42(1.22-1.66)$ & $2.59(1.93-3.48)$ & $1.25(1.08-1.46)$ & $1.59(1.12-2.27)$ \\
\hline Outer regional & $1.09(0.90-1.32)$ & $0.89(0.74-1.08)$ & $2.06(1.75-2.42)$ & $2.05(6.00-5.46)$ & $1.46(1.25-1.71)$ & $1.11(0.73-1.70)$ \\
\hline $\begin{array}{l}\text { Remote/ } \\
\text { very remote }\end{array}$ & $1.61(0.99-2.63)$ & $1.11(0.66-1.87)$ & $3.49(2.09-5.84)$ & $25.63(14.40-45.60)$ & $1.96(1.29-2.97)$ & $4.70(2.29-9.67)$ \\
\hline \multicolumn{7}{|c|}{$\begin{array}{l}\text { Notes: } \\
\text { (a) For self or for wages } \\
\text { (b) Gross household income } \\
\text { (c) Accessibility/Remoteness Index of Australia }\end{array}$} \\
\hline
\end{tabular}




\section{Conclusions}

This study differs from previous reports describing the provision of health services within Australia in that it has examined individual ratings of satisfaction with health service accessibility. We found that people living in regional and remote areas reported dissatisfaction with access to health services. Future studies would be improved by examining in more detail which health services (e.g. medical specialties, allied health services, etc.) are difficult to access and the reasons why.

\section{Acknowledgements}

This project was funded and conducted by the Viertel Centre for Research in Cancer Control, The Cancer Council Queensland. The authors would like to thank the nearly 10,000 residents of Queensland who willingly gave their time to be involved in this research.

\section{References}

1. Australian Institute of Health and Welfare. Rural, Regional and remote Health - Indicators of Health. Canberra (AUST): AIHW; 2005. AIHW Catalogue No.: PHE 59. Rural Health Series no. 5.

2. Australian Bureau of Statistics. 2001 Census of Population and Housing. Australia in Profile: A Regional Analysis. Canberra (AUST): ABS; 2004.

3. Bamford EJ, Dunne L, Taylor DS, Symon BG, Hugo GJ, Wilkinson D. Accessibility to general practitioners in rural South Australia - A case study using geographic information system technology. Med J Aust. 1999;171(1112):614-16

4. Brameld KJ, Holman CDJ. The effect of locational disadvantage on hospital utilisation and outcomes in Western Australia. Health Place. 2006;12(4):490502.

5. Dempsey P, Wilson D, Taylor A, Wilkinson D. Self-reported patterns of health services utilisation: An urban-rural comparison in South Australia. Aust J Rural Health. 2003;11:81-8.

6. Woodcock R, Power R, Kamien M, Waddell C. Consumer satisfaction in two small rural communities: a quick methodology to empower rural communities to assess their own healthcare needs. Aust J Rural Health. 1996;4:96-103.

7. Australian Bureau of Statistics. Regional Population Growth, Australia; 2005 2006. Canberra (AUST); ABS; 20076. Catalogue No.: 3218.0

8. DiSipio T, Rogers C, Newman B, Whiteman D, Eakin E, Fritschi L, et al. The Queensland Cancer Risk Study: behavioural risk factor results. Aust $N Z J$ Public Health. 2006;30(4):375-82.

9. Eckert KA, Taylor AW, Wilkinson D. Does health service utilisation vary by remoteness? South Australian population data and the Accessibility and Remoteness Index of Australia. Aust N Z J Public Health. 2004;28(5):42632.

10. Department of Health and Aged Care. Measuring Remoteness: Accessibility/ Remoteness Index of Australia (ARIA). Canberra (AUST): Commonwealth of Australia; 2000. Occasional Papers: New Series No.: 14.

11. SPSS: statistical package for the social sciences [computer program]. Version 14.0. Chicago (IL): SPSS; 2005.

12. Australian Institute of Health and Welfare. National Report on Health Sector Performance Indicators 2003. Canberra (AUST): AIHW; 2003. AIHW Catalogue No.: HWI 78.

\section{Errata}

\section{doi: 10.1111/j.1753-6405.2008.00242.x}

\section{Correction}

Due to an error in production on ANZJPH 32(2) p110-16, David P. Thomas' et al. article 'The social determinents of being an Indigenous non-smoker' (doi: 10.1111/j.1753-6405.2008.00185.x) was missing the following references:

16. Graham H, Inskip HM, Francis B, Harman J. Pathways of disadvantage and smoking careers: Evidence and policy implications. J Epidemiol Community Health. 2006;60 Suppl II:7-12.

17. Barbeau EM, Kreiger N, Soobader M-J. Working class matters: Socioeconomic disadvantage, race/ethnicity, gender and smoking in NHIS 2000. Am J Public Health. 2004;94:269-78.

18. Human Rights and Equal Opportunity Commission. Bringing them Home: Report of the National Inquiry into the Separation of Aboriginal and Torres Strait Islander Children from their Families. Canberra (AUST): AGPS; 1997.

19. Richmond R, Butler T, Wodak A, Wilhelm K. Break Free and Be Proud of Yourself: Inmate Quit Smoking Program. Sydney (AUST): University of New South Wales; 2006

20. ABC News Online [home page on the Internet]. Sydney (AUST): Australian Broadcasting Corporation; 2005 May 14 [cited 2007 June 13]. Eat Right and Exercise, Abbott Tells Indigenous People: Available from: http://www.abc.net. $\mathrm{au} /$ news/newsitems/200505/s1368440.htm

21. Pearson N. Choice is not enough. The Weekend Australian. 2007 April 28. doi: 10.1111/j.1753-6405.2008.00241.x

\section{Clarification}

The authors of the 'Cost of medications for older women' (doi: 10.1111/j.1753-6405.2008.00174.x) in ANZJPH 32(1) p89, would like to make note of the following in relation to the letter:

\section{Acknowledgements}

The research on which this paper is based was conducted as part of the Australian Longitudinal Study on Women's Health, The University of Newcastle and The University of Queensland, funded by the Australian Government Department of Health and Ageing. We acknowledge Medicare Australia for providing the PBS and MBS data.

The analysis was also supported by a Diabetes Australia Research Trust grant. 